\title{
Physical activity recommendations for public health: development and policy context
}

\author{
Pekka Oja $\cdot$ Sylvia Titze
}

Received: 31 March 2011 / Accepted: 25 May 2011 / Published online: 8 June 2011

(C) European Association for Predictive, Preventive and Personalised Medicine 2011

\begin{abstract}
Physical activity recommendations summarise the evidence on how much and what kind of physical activity enhance health and suggest target activity levels for different population groups. According to the recommendations by the U.S. Department of Health and Human Services and WHO children and youth are advised to do at least $1 \mathrm{~h}$ of moderate- to vigorous-intensity physical activity every day. Adults and older adults are recommended to do a minimum of $150 \mathrm{~min}$ moderate-intensity or 75 min vigorous-intensity aerobic activity or their equivalent combination per week, and muscle-strengthening activities. The physical activity recommendations are population-targeted guidelines and exploit primarily the potential of disease prevention. The recommendations form a solid foundation for promotional policies, programmes, interventions, and counselling. Many European countries have included physical activity in their national health and other policies, but there remains a need to adopt the newest physical activity recommendations nationally and to design national physical activity plans.
\end{abstract}

Keywords Public health $\cdot$ Health promotion P Prevention . Policy

P. Oja $(\bowtie)$

UKK Institute for Health Promotion Research,

P.O.Box 30, 33501 Tampere, Finland

e-mail: pekka.oja@uta.fi

S. Titze

Institute of Sport Science, University of Graz,

Mozartgasse 14,

8010 Graz, Austria

\section{Background}

The World Health Organisation's (WHO) Global Strategy on Diet Physical Activity and Health [1] is a landmark document in recognising physical inactivity as a key risk factor in the prevention and control of chronic diseases. It encourages the member states to place physical activity promotion in the national health promotion policies. To further support the member states in the implementation of the global strategy on a national level, the WHO has provided guidance for population based approaches [2] and for interventions [3] to increase physical activity.

Evidence-based physical activity recommendations for health have been issued since 1995. New recommendations based on updated scientific evidence have been published during the past few years. As physical activity recommendations are issued to summarise the evidence on the relationship between physical activity and health, to indicate the respective dose-response relations, and to recommend how much and what kind of physical activity enhances health, they should inform and guide physical activity promotion for public health. This has happened in a variety of ways globally and in Europe. Recently Oja et al. [4] argued that a review of the current physical activity recommendations in Europe should be undertaken in view of the most recent evidence.

The published physical activity recommendations for health have a population perspective. They combine those characteristics of physical activity (i.e. type, frequency, intensity, duration) that have known health effects into a united activity statement. The message is meant to be simple and informative enough to guide people in their physical activity behaviour in order to increase the population level of physical activity. Due to the multitude of health benefits of physical activity even moderate 
increase in population activity level is likely to result in considerable public health gains.

In this chapter we summarise the development and the current status of physical activity recommendations for health, and describe recent policy and programme development with particular focus on the European situation.

\section{Developing physical activity recommendations}

Physical activity recommendations for health are based on the available evidence of the dose-response relationship between physical activity and health. The most up-to-date review of this evidence was reported in the U.S. Physical Activity Guidelines Advisory Committee report in 2008 [5]. Regarding children and youth the existing evidence (mostly strong according to standard evidence rating) suggest that regular participation on 3 or more days per week in each of the following activities results in comprehensive health benefits: 1) resistance exercise enhances muscular strength in large muscles of the trunk and the limbs, 2) vigorous aerobic exercise improves cardio-respiratory fitness and cardiovascular and metabolic disease risk factors, and 3) bone-loading activities promote bone health. However, it is not possible to draw definitive conclusions regarding the minimal or optimal doses of health-enhancing physical activity. Among adults and older adults evidence (mostly strong) shows that aerobic activities lower the rates of all-cause mortality and major noncommunicable diseases (cardiovascular mortality and morbidity, metabolic syndrome, type 1 and 2 diabetes, obesity, colon and breast cancer) and improve their biomarkers, and support better functional and mental health. Muscle strengthening exercises maintain muscular and bone health, improve musculoskeletal functional status, and reduce the falls. The greatest public health gains can be obtained through aerobic type physical activities totalling 500 to 1000 MET-minutes per week (e.g. a person who walks with the intensity of 3 times higher than quiet sitting has to walk $166 \mathrm{~min}$ in a week to achieve 500 MET-minutes), and through progressive muscle strengthening exercises targeting all major muscle groups on two or more days per week

During the past two decades a great amount of new evidence on the health benefits of physical activity and on the respective dose-response relationships have accumulated. This gain in evidence is reflected in the published recommendations. In the following the development of the most advanced consensus recommendations is described.

The most widely known evidence-based physical activity recommendation for public health was issued in 1995 by the U.S. Centres for Disease Control and Prevention (CDC) and the American College of Sports Medicine (ACSM) [6]. It reads: "Every U.S. adult should accumulate $30 \mathrm{~min}$ or more of moderate-intensity physical activity on most, preferably all, days of the week". This recommendation has been adopted worldwide and in many European countries. Recently, two extensively documented evidence-based physical activity recommendations have been presented in the United States: the first by the American Heart Association (AHA) \& ACSM [7, 8] followed by the U.S. Department of Health and Human Services (US DHHS) [9].

According to the 2007 AHA \& ACSM recommendation [7] all healthy adults need moderate-intensity aerobic physical activity for a minimum of $30 \mathrm{~min}$ on 5 days each week or vigorous-intensity aerobic activity for a minimum of 20 min on 3 days each week in order to promote and maintain their health (Table 1). This recommendation also notes that combinations of moderate- and vigorousintensity activity can be performed to meet the recommended activity level. In addition, the recommendation includes guidelines for activities that increase or maintain musculoskeletal health. The recommendation for older adults [8] is similar to the adult recommendation with additional guidance for special activities for flexibility and balance.

The US DHHS 2008 recommendations (Table 2) are based on an extensive review of literature [5]. The recommendations for adults and older adults are in principal similar to the 2007 ACSM \& AHA recommendations, but they recommend total weekly time (150 $\mathrm{min}$ ) rather than the number of sessions per week (five times $30 \mathrm{~min}$ per week). The 2008 document includes also specific recommendations for young people, for people with disabilities and for pregnant and postpartum women. Accordingly, children and adolescents should do at least $1 \mathrm{~h}$ physical activity every day, which should include moderate- and vigorous-intensity aerobic activities and muscle-strengthening and bone-strengthening activities. The recommendation for older adults is similar to the adult recommendation in regard to aerobic and musclestrengthening activity and also includes activities for flexibility and balance. Also the recommendation for adults with disabilities follows largely the adult recommendation, but activities should be done according to people's abilities. Healthy pregnant and postpartum women are advised to engage in moderate-intensity physical activity according to the adult recommendation, and those who habitually engaged in vigorous-intensity activities can continue to do so during pregnancy and postpartum period with the support of their health-care provider.

As general principles the US DHHS 2008 recommendations [9] state:

- some activity is better than no activity

- many health benefits increase with the increase of the intensity, frequency and/or duration of activity

- the health benefits of physical activity greatly outweighs the health risks 
Table 1 ACSM \& AHA recommendations [7, 8]

Target group Recommendation Note

Adults (aged 18-65)

Older adults (aged 65+)

\begin{abstract}
Aerobic activity All healthy adults need moderateintensity aerobic physical activity for a minimum of $30 \mathrm{~min}$ on 5 days a week or vigorous-intensity aerobic activity for a minimum of 20 min on 3 days a week.

Also, combinations of moderate- and vigorous-intensity can be performed to meet this recommendation.

Moderate-intensity aerobic activity can be accumulated toward the 30 -min minimum from bouts lasting $10 \mathrm{~min}$ or more.
\end{abstract}

Muscle-strengthening activity Adults will benefit from performing activities that maintain or increase muscular strength and endurance for a minimum of 2 days a week.

It is recommended that $8-10$ exercises be performed on 2 or more non-consecutive days each week using the major muscle groups. To maximise strength development, a resistance should be used that allows 8-12 repetitions of each exercise resulting in volitional fatigue.

Aerobic activity Same as for adults.

Muscle-strengthening activity Same as for adults with the exception that the intensity should be moderate to high.

Flexibility activity Older adults should perform activities that maintain or increase flexibility on at least 2 days each week for at least 10 min each day.

Balance exercise Community-dwelling older adults with substantial risk of falls should perform exercises that maintain or improve balance.
Note

The recommended amount of aerobic activity is in addition to routine activities of daily life of light intensity or lasting less than $10 \mathrm{~min}$ in duration.

Muscle-strengthening activities include a progressive weight-training programme, weight-bearing calisthenics, stair climbing, and similar resistance exercises that use the major muscle groups.

Participation in aerobic and muscle-strengthening activities above minimum recommended amounts provides additional health benefits and results in higher levels of fitness. Older adults should exceed the minimum recommended amounts of physical activity if they have no conditions that preclude higher amounts of physical activity.
- the health benefits of physical activity are in a market degree independent of gender, race and ethnicity

The U.S. 2008 recommendations were largely adopted by the World Health Organisation in its global physical activity recommendations published in 2010 [10] (Table 3). They include recommendations for children and youth, adults and older adults. Children and youth are advised to do at least $1 \mathrm{~h}$ of moderate- to vigorous-intensity physical activity every day. This should be mostly aerobic, but it should include also muscle- and bone-strengthening activities. Adults are recommended to do a minimum of $150 \mathrm{~min}$ moderate-intensity or $75 \mathrm{~min}$ vigorous-intensity aerobic activity or their equivalent combination per week, and in addition muscle-strengthening activities on at least 2 days a week. For additional health benefits double the amount of weekly activity is recommended. The recommendation for older adults is the same as for adults with regard to aerobic and muscle-strengthening activities. Older adults with poor mobility should also do activities that enhance balance and prevent falls.

The recent recommendations do not refute the 1995 recommendation, but they include new specifications as well as several new elements compared to the earlier recommendation. The most notable new elements are the new target groups and the inclusion of vigorous-intensity activities and activities for muscle strength, flexibility, balance, and bone health. Another difference is that the latest recommendations are based on the total weekly activity time rather than number of sessions of given duration per week, although the new recommendations advise spreading the activity throughout the week. While the 1995 recommendation introduced life-style activities as health-enhancing physical activity, the latest recommendations, by the inclusion of vigorous-intensity activities, also acknowledge the potential of sportive activities to contribute to public health.

As evidence on the health benefits of physical activity continues to accumulate, recommendations need to be refined accordingly. Outcome-specific dose-response evidence will allow for outcome-specific recommendations. With greater participation especially in more vigorous activities the issue of the health risks and their prevention becomes increasingly important. Currently the consensus is that the health benefits of physical activity far outweighs the health risks, and there is no evidence to show that persons who consult with a health care provider before increasing their physical activity receive more benefits or suffer fewer adverse effects than persons who do not [5]. The growing research evidence on the negative health 
Table 2 U.S. Department of Health and Human Services' recommendations [9]

\begin{tabular}{|c|c|c|}
\hline Target group & Recommendation & Note \\
\hline $\begin{array}{l}\text { Children and } \\
\text { adolescents } \\
\text { (aged 6-17) }\end{array}$ & $\begin{array}{l}\text { Children and adolescents should do } 60 \mathrm{~min}(1 \mathrm{~h}) \text { or more of } \\
\text { physical activity daily. } \\
\text { Aerobic: Most of the } 60 \text { or more minutes a day should be either } \\
\text { moderate- or vigorous-intensity aerobic physical activity, and } \\
\text { should include vigorous-intensity physical activity at least } 3 \text { days }\end{array}$ & $\begin{array}{l}\text { It is important to encourage young people to } \\
\text { participate in physical activities that are appropriate } \\
\text { for their age, that are enjoyable, and that offer } \\
\text { variety. }\end{array}$ \\
\hline
\end{tabular}
should include vigorous-intensity physical activity at least 3 days a week.

Muscle-strengthening: As part of their 60 or more minutes of daily physical activity, children and adolescents should include muscle-strengthening physical activity on at least 3 days of the week.

Bone-strengthening: As part of their 60 or more minutes of daily physical activity, children and adolescents should include bonestrengthening physical activity on at least 3 days of the week.

Adults

(aged 18-64)

Older adults

(aged 65 and older)

Women during pregnancy and the postpartum period

Adults with disabilities
Adults should do at least $150 \mathrm{~min}(2 \mathrm{~h}$ and $30 \mathrm{~min})$ a week of moderate-intensity, or $75 \mathrm{~min}(1 \mathrm{~h}$ and $15 \mathrm{~min})$ a week of vigorous-intensity aerobic physical activity, or an equivalent combination of moderate- and vigorous-intensity aerobic activity. Aerobic activity should be performed in episodes of at least $10 \mathrm{~min}$, and preferably, it should be spread throughout the week. For additional and more extensive health benefits, adults should increase their aerobic physical activity to $300 \mathrm{~min}(5 \mathrm{~h})$ a week of moderate-intensity, or $150 \mathrm{~min}$ a week of vigorous-intensity aerobic physical activity, or an equivalent combination of moderate- and vigorous-intensity activity. Additional health benefits are gained by engaging in physical activity beyond this amount.

Adults should also do muscle-strengthening activities that are moderate or high intensity and involve all major muscle groups on 2 or more days a week, as these activities provide additional health benefits.

The guidelines for older adults are the same as for adults regarding aerobic and muscle-strengthening activities.

In addition older adults should do exercises that maintain or improve balance if they are at risk of falling.

Healthy women who are not already highly active or doing vigorous-intensity activity should get at least $150 \mathrm{~min}(2 \mathrm{~h}$ and $30 \mathrm{~min}$ ) of moderate-intensity aerobic activity per week during pregnancy and the postpartum period. Preferably, this activity should be spread throughout the week.

Pregnant women who habitually engage in vigorous-intensity aerobic activity or are highly active can continue physical activity during pregnancy and the postpartum period, provided that they remain healthy and discuss with their health-care provider how and when activity should be adjusted over time.

Adults with disabilities, who are able to, should get at least $150 \mathrm{~min}$ per week $(2 \mathrm{~h}$ and $30 \mathrm{~min})$ of moderate-intensity, or $75 \mathrm{~min}(1 \mathrm{~h}$ and $15 \mathrm{~min})$ per week of vigorous-intensity aerobic activity, or an equivalent combination of moderate- and vigorousintensity aerobic activity. Aerobic activity should be performed in episodes of at least $10 \mathrm{~min}$, and preferably, it should be spread throughout the week.

They should also do muscle-strengthening activities of moderate or high intensity that involve all major muscle groups on 2 or more days per week as these activities provide additional health benefits.
All adults should avoid inactivity. Some physical activity is better than none, and adults who participate in any amount of physical activity gain some health benefits.

When older adults cannot do 150 min of moderateintensity aerobic activity a week because of chronic conditions, they should be as physically active as their abilities and conditions allow.

All older adults should avoid inactivity. Some physical activity is better than none, and older adults who participate in any amount of physical activity gain some health benefits.

When adults with disabilities are not able to meet the guidelines, they should engage in regular physical activity according to their abilities and should avoid inactivity.

Adults with disabilities should consult their healthcare providers about the amounts and types of physical activity that are appropriate for their abilities. 
Table 3 WHO global recommendations [10]

\begin{tabular}{|c|c|c|}
\hline Target group & Recommendation & In addition \\
\hline $\begin{array}{l}\text { Children and youth } \\
\text { (aged 5-17) }\end{array}$ & $\begin{array}{l}\text { Accumulate at least } 60 \text { min of moderate-to vigorous- } \\
\text { intensity physical activity daily. Most of the daily } \\
\text { physical activity should be aerobic. Vigorous-intensity } \\
\text { activities should be incorporated, including those that } \\
\text { strengthen muscle and bone, at least } 3 \text { times per week. }\end{array}$ & $\begin{array}{l}\text { Amounts of physical activity greater than } 60 \mathrm{~min} \\
\text { provide additional health benefits. }\end{array}$ \\
\hline Adults (aged 18-64) & $\begin{array}{l}\text { At least } 150 \text { min of moderate-intensity aerobic physical } \\
\text { activity throughout the week, or at least } 75 \text { min of } \\
\text { vigorous-intensity aerobic physical activity throughout } \\
\text { the week, or an equivalent combination of moderate- } \\
\text { and vigorous-intensity activity. Aerobic activity should } \\
\text { be performed in bouts of at least } 10 \text { min duration. } \\
\text { Muscle-strengthening activities should be done } \\
\text { involving major muscle groups on } 2 \text { or more days a } \\
\text { week. }\end{array}$ & $\begin{array}{l}\text { For additional health benefits, adults should increase } \\
\text { their moderate-intensity aerobic physical activity to } \\
300 \text { min per week, or engage in } 150 \text { min of } \\
\text { vigorous-intensity aerobic physical activity per } \\
\text { week, or an equivalent combination of moderate- } \\
\text { and vigorous-intensity activity. }\end{array}$ \\
\hline $\begin{array}{l}\text { Older adults (aged } 65 \\
\text { and older) }\end{array}$ & $\begin{array}{l}\text { The recommendation for aerobic and muscle- } \\
\text { strengthening activities is the same as for adults. }\end{array}$ & $\begin{array}{l}\text { When older adults cannot do the recommended } \\
\text { amounts of physical activity due to health } \\
\text { conditions, they should be as physically active as } \\
\text { their abilities and conditions allow. }\end{array}$ \\
\hline & $\begin{array}{l}\text { In addition older adults with poor mobility should } \\
\text { perform physical activity to enhance balance and } \\
\text { prevent falls on } 3 \text { or more days per week. }\end{array}$ & \\
\hline
\end{tabular}

effects from lack of physical activity, which may be independent of physical activity, is likely to provide in the near future sufficient knowledge base for the provision of recommendations on physical inactivity.

\section{Policy context}

Physical activity recommendations as such are not sufficient to increase physical activity levels of populations [11]. However, as the recommendations provide evidence-based summary of the health benefits of physical activity, they form solid foundation for promotional policies and strategies as well as metrics for monitoring physical activity levels of populations.

Based on their latest physical activity recommendations the U.S. Government has issued a national plan [12] for how to move from recommendations to action. Also several European countries are in the process of establishing national recommendations followed by a respective action plan. Most recently, Finland [13] and Austria [14] have issued national physical activity recommendations, based on the latest scientific evidence. The United Kingdom is in the process of issuing their national recommendations, and at least Sweden is preparing to develop their own recommendations.

The WHO's guide for population-based approach to physical activity [2] is meant to assist the member states and other stakeholders in the development and implementation of a national physical activity plan and provide guidance on policy options for effective promotion of physical activity at the national regional and local level. The guide lists the following elements to be important for successful policies and plans: high-level political commitment, integration in national policies, identification of national goals and objectives, overall health goals, specific objectives, funding, support from stakeholders, cultural sensitivity, integration of physical activity within other related sectors, multi-sectorial coordination, multiple intervention strategies, targeting whole populations as well as specific population groups, clear identity, implementation at different levels within the local setting, leadership and workforce development, dissemination, and monitoring and evaluation. This guide further provides a stepwise framework for planning and implementation and examples of areas for action.

Another guidebook by WHO Europe presented a European framework for the promotion of physical activity [15]. It was targeted to policy makers and experts in member states to design and implement physical activitypromoting policy and action as part of national public health agenda and through multi-sectorial cooperation. The document includes sections on the challenge, guiding principles for action, guidelines for action, and on setting goals and measuring success.

HEPA Europe, the European network for the promotion of health-enhancing physical activity, conducted in close collaboration with the WHO Regional Office for Europe an analysis of national policy documents on the promotion of physical activity [16]. Forty-nine national policy documents 
were identified: 29 in health promotion, 12 in transport, 7 in sports, and one in environment. The policies addressed important project elements such as goals, implementation, timeframe, responsible body and evaluation, but there was limited consideration for inter-sectorial collaboration and targeting groups most in need for increased physical activity.

\section{National physical activity programmes}

In addition to global, European and national physical activity policy development, evidence and experiences on physical activity programmes are increasing. Cavill et al. [17] illustrated a theory-based promotional approach by analysing national physical activity promotion programmes from Finland, England, and Switzerland. The general approach was based on four tasks: (1) using the evidence for the health benefits of physical activity to make the case and increase action by policy makers, (2) conducting surveillance to collect evidence on the prevalence of physical activity, (3) reviewing evidence on 'what works' in increasing physical activity and influencing practice, and (4) evaluating practice.

In task 1 all three countries took a similar approach by drawing together the existing evidence on the health benefits of physical activity. In task 2 Finland and Switzerland collected systematic trend data and used them for advocacy, while in England many changes in survey methodology provided poor trend data. In task 3 England used a systematic approach to reviewing the evidence on what works while the other countries relied mainly on individual evaluation studies. Concerning the evaluation of practices, a significant challenge for improvement remains, because all three countries relied much on experience rather than on evidence. The analysis showed clear differences in how the four tasks were undertaken in these countries and demonstrated how cultural and political factors strongly influence the promotional efforts.

\section{Summary and outlook}

Physical activity guidelines and recommendations have evolved from earlier fitness- and individual-oriented exercise prescriptions to public health-oriented recommendations. The new health-related recommendations, started by the CDC \& ACSM recommendation in 1995 [6], consider all physical activity, whether at work or home, or during leisure or transport, to be potentially health-enhancing. The 1995 recommendation emphasised daily or almost daily moderate-intensity activity, such as walking, cycling and gardening, and targeted primarily adult populations. Based on new evidence, more recent recommendations emphasise the total weekly activity and include wider spectrum of activities with regard to the type and intensity. Thus activities for muscle and bone strength and flexibility, and vigorous-intensity activities are also recommended. The newer recommendations consider also more target groups in order to provide guidance to the whole population.

The WHO and WHO Europe have published guidelines to assist the member states and other stakeholders in the development and implementation of national physical activity plan and to provide guidance on policy options for effective promotion of physical activity at national and sub-national level. Most European countries have integrated the promotion of physical activity at least to some extent in their national health and other policies. However, there is a need to continue to update the policies both methodologically and substantially. Three national physical activity programmes for adults have been systematically analysed. They illustrate the importance of the cultural and political environment in the planning and implementation of such programmes as well as the strengths and weaknesses of them.

A number of evidence-based physical activity recommendations and policy development guidelines are available to support the design and implementation of physical activity policies, programmes and interventions to promote public health. Leading physical activity recommendations have been issued by U.S. experts and authorities and policy guidelines have been developed by the World Health Organisation. While there has been diffusion of this information to national scenes globally and in Europe, this has taken place in rather spontaneous and unorganised way. Although the European countries are beginning to increasingly adopt the latest scientific knowledge in developing efforts to promote physical activity for public health, there remains a need to adopt the newest recommendations nationally and to design national physical activity plans.

The physical activity recommendations discussed in this review are population-targeted. The expected public health improvement are primarily based on the preventive effects of activity on specific diseases, which include many cardiovascular and metabolic diseases, some cancers and osteoporosis, and from the functional improvements. The recommendations are designed to guide the promotion of physical activity for public health. Their message is intended to inform the general public as well as health policy makers and practitioners what kind and how much physical activity is needed for health benefits conducive to public health gains. These recommendations can also be used by health care specialists to advice patients and customers on general health-enhancing physical activity behaviour. 
The physical activity recommendations are not meant to be used as such for individualised exercise prescriptions for the treatment of specific diseases. However, the outcomespecific dose-response evidence, on which the recommendations are based, can be used when designing activity treatment for a given disease, but this requires individualised dosage according to the clinical status of an individual. Currently this has to rely on existing evidence, which allows for crude activity specification for given types of disease states, e.g. aerobic activity for cardiovascular and metabolic diseases or resistance exercises for musculoskeletal diseases. As new evidence on the dose-responses of physical activity and specific disease states accumulates, it is foreseeable that more outcome-specific activity dosage will be possible in the future.

\section{References}

1. WHO. Global Strategy on Diet, Physical Activity and Health. 2004. www.who.int/dietphysicalactivity/strategy/eb11344/strategy_ english_web.pdf. Accessed 1 February 2011.

2. WHO. A Guide for Population-based Approaches to Increasing Levels of Physical Activity. Implementation of the WHO Global Strategy on Diet, Physical Activity and Health. 2007. http://www. who.int/entity/dietphysicalactivity/PA-promotionguide.pdf/. Accessed 20 January 2011.

3. WHO. Interventions on diet and physical activity: what works: summary report. Geneva, World Health Organisation. 2009. http:// www.who.int/dietphysicalactivity/summary-report-09.pdf. Accessed 30 January 2011.

4. Oja P, Bull F, Fogelholm M, Martin WM. Physical activity recommendations for health: what should Europe do? BMC Public Health. 2010;10:10.

5. Physical Activity Guidelines Advisory Committee. Physical Activity Guidelines Advisory Committee Report, 2008.Washington, DC: U.S. Department of Health and Human Services. 2008. http://www.health. gov/paguidelines. Accessed 9 February 2011.

6. Pate RR, Pratt M, Blair SN, Haskell WL, Macera CA, Bouchard $\mathrm{C}$, et al. Physical activity and public health. a recommendation from the centres for disease control and prevention and the American College Of Sports Medicine. JAMA. 1995;273:402-7.

7. Haskell WL, Lee I-M, Pate RR, Powell KE, Blair SN, Franklin BA, et al. Physical activity and public health. Updated recom- mendations for adults from the American College of Sports Medicine and the American Heart Association. Circulation. 2007;116:1081-93.

8. Nelson ME, Rejeski WJ, Blair SN, Duncan PW, Judge JO, King $\mathrm{AB}$, et al. Physical activity and public health in older adults. Recommendation from the American College of Sports Medicine and the American Heart Association. Circulation. 2007;116:1094105.

9. U.S. Department of Health and Human Services. 2008 Physical Activity Guidelines for Americans. Washington, DC: U.S. Department of Health and Human Services. 2008. http://www. health.gov/paguidelines. Accessed 28 January 2011.

10. WHO. Global recommendations on physical activity for health. 2010. http://whqlibdoc.who.int/publications/2010/9789241599979_eng.pdf. Accessed 30 January 2011.

11. Troiano RP, Haskell WL. The role of physical activity guidelines in preventing physical inactivity. In: Brown WJ, Havas E, Komi PV (Eds.), Promoting Sport for All. Benefits and strategies for the 21 st century. Proceedings, plenary sessions.XIII World Sport for All Congress, 14-17 June, 2010, Jyväskylä, Finland. LIKES Research Reports on Sport and Health 235. 2010. pp. 33-39.

12. National Physical Activity Plan. National Plan for Physical Activity. 2010. http//www.physicalactivityplan.org. Accessed 31 March 2011.

13. Fogelholm M, Suni J, Rinne M, Oja P, Vuori I. Physical activity pie: a graphical presentation integrating recommendations for fitness and health. J Phys Act Health. 2005;2:391-6.

14. Titze S, Ring-Dimitriou S, Schober PH., Halbwachs C, Samitz G, Miko HC, Lercher P, Stein KV, Gäbler C, Bauer R, Gollner E, Windhaber J, Bachl N, Dorner TE \& Arbeitsgruppe KörperlicheAktivität/Bewegung/Sport der Österreichischen Gesellschaft für Public Health. Bundesministerium für Gesundheit, Gesundheit Österreich $\mathrm{GmbH}$, Geschäftsbereich Fonds Gesundes Österreich (Hrsg.). Österreichische Empfehlungen für gesundheitswirksame Bewegung. Wien: Eigenverlag. 2010. http://www.fgoe.org/pressepublikationen/downloads/forschung/bewegungsempfehlungen/ 2010-04-28.1864800615. Accessed 24 February 2011.

15. WHO Europe. Steps to health. A European framework to promote physical activity for health.Copenhagen, WHO Regional Office for Europe. 2007. http://www.euro.who.int/_data/assets/pdf_file/ 0020/101684/E90191.pdf. Accessed 30 January 2011.

16. Daugbjerg SB, Kahlmeier S, Racioppi F, Martin-Diener E, Martin $\mathrm{B}$, Oja P, et al. Promotion of physical activity in the European region: Content analysis of 27 national policy documents. J Phys Act Health. 2009;6:805-17.

17. Cavill N, Foster C, Oja P, Martin BW. An evidence-based approach to physical activity promotion and policy development in Europe: contrasting case studies. IUHPE-Promotion \& Education. 2006;13:20-7. 